\title{
Reverse As-built Transformer Design Method
}

\author{
P.S. Bodger M.C. Liew \\ Department of Electrical and Electronic Engineering, \\ University of Canterbury, Private Bag 4800, \\ Christchurch, New Zealand
}

Keywords: Transformer, design, reverse, high voltage, power 


\begin{abstract}
A reverse approach to designing as-built transformers is presented in this paper. The physical characteristics and dimensions of the windings and core are the specifications. By manipulating the amount and type of material actually to be used in the construction of the transformer, its performance can be determined. Such an approach is essentially the opposite of the conventional transformer design method. The method is applied to two sample high voltage transformers. The measured performance of the transformers verifies the usefulness of using this reverse design approach.
\end{abstract}




\section{Introduction}

From a manufacturer's perspective it is convenient to design and produce a set range of transformer sizes. Usually, the terminal voltages, VA rating and frequency are specified. These specifications determine the materials to be used and their dimensions. This approach to transformer design has been utilised and presented in detail in standard textbooks $[1,2]$. It has been used as a design tool for teaching undergraduate power system courses at universities [3-12]. In addition, it has also been used extensively in designing transformers for switched mode power supplies [13-17]. Finite Element Analysis has also been applied, concurrent with the above approach, to aid the overall design process [18-22].

However, by designing to rated specifications, consideration is not explicitly given to what materials and sizes are actually available. Core and winding material suppliers offer catalogues of preferred sizes, particularly so for smaller rating devices. This reflects the supplier's manufacturing capabilities in extrusion, rolling and forming tools and equipment. It is not economic to offer customers any size and shape they require. It is possible that an engineer, having designed a transformer, may then find the material sizes do not exist. The engineer may then be forced to use available materials and 
consequently the performance of the actual transformer that is built is likely to be significantly different from that of the design calculations. Due to the inexactness of estimating actual winding dimensions, the leakage reactance in particular may be miscalculated. The leakage reactance is a dominant parameter in power system studies involving transformers.

A reverse design approach is presented in this paper, whereby the physical characteristics and dimensions of the windings and core are the specifications. By manipulating the amount and type of material actually to be used in the construction of the transformer, its performance can be determined. Such an approach lends itself to designing transformers using what is available from suppliers. This is essentially the opposite of the conventional transformer design method. It allows for customized design, as there is considerable flexibility in meeting the performance required for a particular application. This can allow matched rated, cost effective solutions to power supply requirements, as against the traditional practice of over-rating the transformer component of a power supply because of batch construction and fixed sized transformer ratings. 


\section{Reverse Transformer Design}

Consideration is given to the layout of the core and windings of a two winding transformer, as depicted in Figure 1. The laminated core occupies the central space. The windings are wrapped around the core, with the LV winding inside the high voltage winding. Insulation is allowed for between the core and windings, between windings, around winding wire and in between each layer of winding if required. No explicit account of the insulation, which determines the capacitance, is usually made in the performance calculations for fundamental frequency transformers. However, insulation thickness does affect spacial displacements and hence is accounted for in calculating equivalent circuit parameters.

The yokes and limbs of the core are additional to this. They depend on whether the transformer is a "core" or "shell" type [23] and have dimensions determined by the boundaries of the windings and cross-section of the core. Usually, for smaller transformers, the core laminations come in discrete sizes. For shell type cores they may be fabricated to eliminate waste from stamping from rolled strip. Such "scrapless" EI cores [24] have specific ratios for their window dimensions and magnetic path sizes. For larger transformers it may be economic to select set sizes which minimize lamination material wastage 
through stepped circular cores.

A transformer profile showing known material characteristics and dimensions is depicted in Figure 2. The winding and core material resistivities and permeabilities are specifications. The core cross-section dimensions (diameter for a circular core and side lengths for a rectangular core) are selected from catalogues of available materials. A core length is chosen. Laminations that are available can be specified in thickness and a space factor estimated from the ratio of iron to total volume. Other factors such as material density and cost per unit weight assist in material ordering when totals are known.

For each winding, the wire size can be selected, again from catalogues. They also specify insulation thickness. The designer can then specify how many layers of each winding are wound. Insulation space between layers allows for high voltage applications. Again, material density and cost per unit weight assist in material ordering when totals are known.

The only rating requirements are the primary voltage and frequency, $f$. The secondary voltage and transformer VA rating are a consequence of the construction of the transformer.

With reference to Figure 2, the number of turns on the windings is estimated 
to be:

$$
\begin{aligned}
& N_{1}=\frac{L_{1} l_{c}}{t_{1}} \\
& N_{2}=\frac{L_{2} l_{c}}{t_{2}}
\end{aligned}
$$

where $L_{1}=$ number of primary winding layers

$$
\begin{aligned}
L_{2}= & \text { number of secondary winding layers } \\
l_{c}= & \text { length of the core } \\
t_{1}, t_{2}= & \text { thicknesses of primary and secondary winding wires, } \\
& \text { respectively. This includes the wire insulation. }
\end{aligned}
$$

Having obtained the dimensions of the transformer windings and core, and the material characteristics being known, the components of a transformer equivalent circuit can be calculated. The equivalent circuit shown in Figure 3 is often used for supply frequencies [25].

Calculations can be divided into three parts:

- resistance models

- inductive reactance models

- size, weights, costs and performance 


\subsection{Resistance Models}

The resistance models depict the core loss resistance $\left(R_{c}\right)$ and the primary $\left(R_{1}\right)$ and secondary $\left(R_{2}\right)$ winding resistances.

\subsubsection{Core loss Resistance}

The losses in the core consist of two major components; the hysteresis loss and the eddy current loss. The hysteresis loss can be calculated using [25]

$$
\begin{aligned}
& P_{h}=k_{h} f B^{x} \\
& \text { where } k_{h}=\text { a constant (material dependant) } \\
& \qquad x={\text { Steinmetz } \text { factor }^{1}}^{1}
\end{aligned}
$$

This calculation requires an estimate of the magnetic flux density which can be obtained from the "transformer equation" as [25]

$$
\begin{aligned}
& B=\frac{V_{1}}{4.44 N_{1} f A_{c}} \\
& \text { where } V_{1}=\text { primary voltage }
\end{aligned}
$$

The value of $B$ can be checked against an optimal value for the core material.

The eddy current loss is expressed as [26]

$$
P_{e c}=\frac{c_{l}^{2}}{12 \rho_{c}} \frac{l_{c}}{N_{1}^{2} A_{c}} e_{1}^{2}
$$

\footnotetext{
${ }^{1}$ The Steinmetz factor has a value between 1.8 to 2.5 .
} 
where $c_{l}=$ lamination thickness

$$
\begin{aligned}
& \rho_{c}=\text { operating resistivity of the core } \\
& A_{c}=\text { cross-sectional area of the core } \\
& e_{1}=\text { induced primary winding voltage }
\end{aligned}
$$

The variation of resistivity with temperature of all materials should be accounted for, since the transformer will be heated up under operation. The operating resistivity at temperature $T^{\circ} \mathrm{C}$ is

$$
\rho=\frac{(1+\Delta \rho T) \rho_{20^{\circ} C}}{(1+20 \Delta \rho)}
$$

where $\Delta \rho=$ thermal resistivity coefficient

$$
\rho_{20{ }^{\circ} \mathrm{C}}=\text { material resistivity at } 20^{\circ} \mathrm{C}
$$

The hysteresis and eddy current losses can be expressed in terms of the induced voltage $e_{1}$ as

$$
\begin{gathered}
P_{h}=\frac{e_{1}^{2}}{R_{h}} \\
P_{e c}=\frac{e_{1}^{2}}{R_{e c}}
\end{gathered}
$$

where $R_{h}=$ hysteresis loss equivalent resistance

$$
R_{e c}=\text { eddy current loss equivalent resistance }
$$

Thus, as shown in Figure 4 , both $R_{h}$ and $R_{e c}$ can be included in the model as the core loss resistance $R_{c} . R_{c}$ is expressed as

$$
R_{c}=\frac{R_{h} R_{e c}}{R_{h}+R_{e c}}
$$




\subsubsection{Primary Winding Resistance}

The primary winding resistance is

$$
\begin{aligned}
& R_{1}=\frac{\rho_{1} l_{1}}{A_{1}} \\
& \text { where } \rho_{1}=\text { resistivity of the primary winding wire } \\
& l_{1}=\text { effective length of the wire } \\
& A_{1}=\text { cross-sectional area of the wire }
\end{aligned}
$$

The effective length of the primary winding wire is estimated by calculating the length of wire on each layer of the winding, and then summing over all layers, taking into account the increasing diameter of each layer wound around the previous one.

\subsubsection{Secondary Winding Resistance}

The secondary winding resistance is

$$
\begin{aligned}
R_{2}=\frac{\rho_{2} l_{2}}{A_{2}} & \\
\text { where } \rho_{2} & =\text { resistivity of the secondary wire } \\
l_{2} & =\text { effective length of the wire } \\
A_{2} & =\text { cross-sectional area of the wire }
\end{aligned}
$$

As for the primary winding, the effective length of the secondary winding wire is calculated by approximating the length of the wire on each layer of the secondary winding, and then summing over all layers. 


\subsection{Inductive Reactance Models}

The inductive reactance models contain the magnetising reactance $\left(X_{m}\right)$, and the primary $\left(X_{1}\right)$ and secondary $\left(X_{2}\right)$ leakage reactances.

\subsubsection{Magnetising Reactance}

The magnetising reactance is $[27]$

$$
\begin{aligned}
& X_{m}=\frac{\omega N_{1}^{2} \mu_{o} \mu_{r c} A_{c}}{l_{c}} \\
& \text { where } \mu_{o}=\text { permeability of free space } \\
& \quad=4 \pi \times 10^{-7} \mathrm{Hm}^{-1} \\
& \mu_{r c}=\text { relative permeability of core } \\
& \omega=2 \pi f
\end{aligned}
$$

\subsubsection{Primary and Secondary Leakage Reactances}

The primary and secondary leakage reactances are assumed to be the same and are each half of the total transformer leakage reactance [27-29].

$$
\begin{aligned}
X_{1}=X_{2}= & \frac{1}{2} \frac{\omega \mu_{o} N_{1}^{2} 4 \tau_{12} \delta^{\prime}}{l_{c}} \\
\text { where } \tau_{12} & =\text { winding thickness factor } \\
& =d_{1}+\Delta d+d_{2} \text { (see Figure 2) } \\
\delta^{\prime} & =\frac{d_{1}+d_{2}}{3}+\Delta d
\end{aligned}
$$




\subsection{Weights, Costs and Performance}

The weight of each of the core, primary winding and secondary winding is calculated using

$$
\begin{aligned}
& \text { Weight }=\gamma \mathcal{V} \\
& \begin{aligned}
\text { where } \gamma=\text { material density } \\
\qquad \mathcal{V}=\text { volume of the material used }
\end{aligned}
\end{aligned}
$$

The total weight of the transformer is then the sum of the weights of all the parts. No allowance is made for the insulation as this is generally a minor component.

Next, the cost of each of the parts is calculated:

$$
\begin{aligned}
& \text { Cost }=\text { Weight } \times C_{w g t} \\
& \text { where } C_{w g t}=\text { material cost per weight }
\end{aligned}
$$

The total cost can be obtained by summing the costs of all the individual parts.

The performance of the transformer under open circuit, short circuit and loaded conditions can be estimated by putting an impedance $Z_{L}=R_{L}+j X_{L}$ across the output and varying its value. From this information, the secondary 
voltage and VA rating of the transformer is directly derived. Further, performance measures of voltage regulation and power transfer efficiency for any load condition can be readily calculated. Finally, the current flows and densities in the windings can be calculated and compared to desired levels to check that the wires selected can withstand the rated current densities. These are a result of the design rather than being initial design specifications.

With this reverse approach to transformer design, if the calculated performance is not what is required, material dimensions can be altered to change the performance. With experience, a few iterations are all that is required before an acceptable solution has been found.

An as-built transformer based on the design will give a different measured performance because of magnetic material non-linearity, minor construction differences, material characteristic variations, and because the equivalent circuit does not exactly model real processes. In the development of new devices, information gained on the performance of the first as-built device can be used to improve the design of the next device built. 


\section{Design Data for Sample Transformers}

To illustrate the reverse approach to transformer design, two single phase, $50 \mathrm{~Hz}$, high voltage transformers have been designed, built and tested. Their nominal ratings are listed in Table 1. Using the reverse design approach, only the frequency and nominal primary voltage are entered as rated data. The secondary voltage and VA rating are a consequence of the design.

Table 1: Nominal ratings of high voltage transformers

\begin{tabular}{|l|c|c|}
\hline Transformer & $\mathbf{\# 1}$ & $\mathbf{\# 2}$ \\
\hline Primary voltage (V) & 240 & 14 \\
\hline Secondary voltage (kV) & 6.24 & 4.56 \\
\hline VA rating (VA) & 200 & 617 \\
\hline
\end{tabular}

Transformer \#1 was designed for the power supply of an electric, water purification device [30]. Transformer \#2 was a model, designed to evaluate the harmonic performance of capacitive voltage transformers. Both transformers were for special applications and not procurable directly from a manufacturer. Further, in both cases, size, weight and cost were premium requirements and influenced the design.

Standard physical values of material permeabilities, resistivities and thermal resistivity coefficients were also entered as data, for the two different steel cores used, and the copper windings, as shown in Table 2. However, the rel- 
ative permeability values for steels do depend on the metallurgical processes that are used in their manufacture and may not be readily available in practice. They may have to be measured. A core stacking factor of 0.95 was estimated for both transformers.

Table 2: Material constants

\begin{tabular}{|l|c|c|c|}
\hline & Core & $\begin{array}{c}\text { Primary } \\
\text { winding }\end{array}$ & $\begin{array}{c}\text { Secondary } \\
\text { winding }\end{array}$ \\
\hline Relative permeability: & 3000 & 1 & 1 \\
Transformer \#1 & 9000 & 1 & 1 \\
Transformer \#2 & $1.8 \times 10^{-7}$ & $1.76 \times 10^{-8}$ & $1.76 \times 10^{-8}$ \\
\hline Resistivity at $20^{\circ} \mathrm{C}(\Omega \mathrm{m})$ & 0.006 & 0.0039 & 0.0039 \\
\hline Coefficient of thermal & & & 50 \\
resistivity $\left(\Omega \mathrm{m} /{ }^{\circ} \mathrm{C}\right)$ & 50 & 50 & 8960 \\
\hline Operating temperature $\left({ }^{\circ} \mathrm{C}\right)$ & 7870 & 8960 & \\
\hline Density $\left(\mathrm{kg} / \mathrm{m}^{3}\right)$ & \multicolumn{2}{|}{} \\
\hline
\end{tabular}

The dimensions of the various components entered as data are shown in Table 3. Here the final values used to build the transformer are listed.

\section{Calculated and measured performances}

The equivalent circuit parameters, referred to the primary, calculated for the transformers using the reverse design method, are presented in Table 4. The measured values, as determined by open circuit and short circuit tests, are also shown.

These show that the reverse design method, with its particular accounting of 
Table 3: Data for reverse transformer design

\begin{tabular}{|l|c|c|}
\hline Transformer & \#1 & \#2 \\
\hline Core: & 66 & 114 \\
Length (mm) & 51 & 152 \\
\hline Width 1 (mm) & 44 & 44 \\
\hline Width 2 (mm) & 2 & 3.25 \\
\hline Core/LV winding insulation thickness (mm) & 5 & 1 \\
\hline LV winding: & 0.8 & 3.55 \\
Number of layers & 0 & 0 \\
\hline Wire diameter (mm) & 0.7 & 6.5 \\
\hline Interlayer insulation thickness (mm) & & \\
\hline LV/HV winding insulation thickness (mm) & 20 & 20 \\
\hline $\begin{array}{l}\text { HV winding: } \\
\text { Number of layers }\end{array}$ & 0.125 & 0.212 \\
\hline Wire diameter (mm) & 0 & 0.09 \\
\hline Interlayer insulation thickness (mm) & & \\
\hline
\end{tabular}

Table 4: Calculated and measured equivalent circuit parameters for sample transformers

\begin{tabular}{|c|c|c|c|c|}
\hline $\begin{array}{c}\text { Equivalent } \\
\text { Circuit } \\
\text { Parameters }\end{array}$ & \multicolumn{2}{|c|}{ Transformer \#1 } & \multicolumn{2}{c|}{ Transformer \#2 } \\
\cline { 2 - 5 } & Calculated & Measured & Calculated & Measured \\
\hline$R_{c}(\Omega)$ & 3419 & 3388 & 24 & 18 \\
\hline$X_{m}(\Omega)$ & 1982 & 1987 & 49 & 41 \\
\hline$R_{\text {wind }}(\Omega)$ & 8.6 & 10.0 & 0.044 & 0.043 \\
\hline$X_{\text {leak }}(\Omega)$ & 1.8 & 2.8 & 0.005 & 0.012 \\
\hline
\end{tabular}


actual dimensions, accurately models the equivalent circuit parameters. The notable exception is with the leakage reactance. This is due to the as-built transformers having slightly different winding spacial arrangements from the design model.

A resistance was placed across the secondary of Transformer \#1 to the give rated load conditions at unity power factor. On the other hand, since Transformer \#2 was designed for capacitive loads, an open circuit condition was used to compare calculated and measured values. All the results are given in Table 5 .

Table 5: Calculated and measured rated load performance for sample transformers

\begin{tabular}{|c|c|c|c|c|}
\hline \multirow{2}{*}{$\begin{array}{c}\text { Performance } \\
\text { Parameters }\end{array}$} & \multicolumn{2}{|c|}{ Transformer \#1 } & \multicolumn{2}{c|}{ Transformer \#2 } \\
\cline { 2 - 5 } & Calculated & Measured & Calculated & Measured \\
\hline$V_{1}(\mathrm{~V})$ & 240 & 240 & 14.05 & 14.05 \\
\hline$I_{1}(\mathrm{~A})$ & 0.84 & 0.76 & 0.66 & 1 \\
\hline$V_{2}(\mathrm{kV})$ & 6.02 & 6.2 & 4.57 & 4.57 \\
\hline$I_{2}(\mathrm{~mA})$ & 30 & 27 & 0 & 0 \\
\hline$P_{1}(\mathrm{~W})$ & 200 & 181 & 8 & 8 \\
\hline Efficiency (\%) & 89 & 92 & 0 & 0 \\
\hline Regulation (\%) & 2.9 & 0.7 & 0.1 & 0.1 \\
\hline
\end{tabular}

The values listed in Table 5 show that the reverse design method gives performance results which are useful in predicting actual performance of as-built transformers. The difference in regulation reflects the difference in the calculated and measured values of the leakage reactance. The zero efficiency 
entered for Transformer \#2 is a matter of definition for this transformer feeding a purely capacitive load where no real power is transferred to the load. A greater than zero efficiency will be recorded when the transformer feeds resistive loads.

\section{Conclusions}

Conventional transformer design starts from a consideration of required frequency, voltage and VA ratings. It estimates a number of factors for the core and winding arrangement, using values that are generally only known to experienced design engineers. They reflect the "art" of transformer manufacture. Core and winding material characteristics are known from standard values or physical measurements. The resultant design may not match what is actually available in materials and hence the predicted performance can be in error.

The alternative presented in this paper is to reverse the design procedure. The dimensions of core and winding materials are entered based on what is available. The overall size, ratings and performance of the transformer can then be predicted.

Sample high voltage transformers have been designed, built and tested. The 
results show the usefulness of the reverse design approach. Such a design philosophy allows for the exploration in the design of transformers with alternative construction options, where flexibility in shape and size is required. 


\section{References}

[1] E. Lowdon, Practical Transformer Design Handbook, McGraw-Hill, Inc., 2nd edition, 1989.

[2] W.T. McLyman, Transformer and Inductor Design Handbook, Dekker, New York, USA, 2nd edition, 1988.

[3] A. Rubaai, "Computer aided instruction of power transformer design in the undergraduate power engineering class", in IEEE Transactions on Power Systems, August 1994, vol. 9, No. 3, pp. 1174-1181.

[4] W.T. Jewell, "Transformer design in the undergraduate power engineering laboratory", in IEEE Transactions on Power Systems, May 1990, vol. 5, No. 2, pp. 499-505.

[5] F. Shahzad and M.H. Shwehdi, "Human-computer interaction of single/three phase transformer design and performance", in Industrial and Commercial Power Systems Technical Conference, May 1997, pp. 193196.

[6] R. Betancourt and W.V. Torre, "The use of a design project as an innovative and practical approach to the teaching of power systems", in IEEE Transactions on Power Systems, February 1989, vol. 4, No. 1, pp. $372-379$. 
[7] W.M. Grady, R. Chan, M.J. Samotyj, R.J. Ferraro, and J.L. Bierschenk, "A pc-based computer program for teaching the design and analysis of dry-type transformers", in IEEE Transactions on Power Systems, May 1992, vol. 7, No. 2, pp. 709-717.

[8] M. Poloujadoff and R.D. Findlay, "A procedure for illustrating the effect of variation of parameters on optimal transformer design", in IEEE Transactions on Power Systems, November 1986, vol. PWRS-1, No. 4, pp. 202-207.

[9] W.H. Kersting, "A method to teach the design and operation of a distribution system", in IEEE Transactions on Power Apparatus and Systems, July 1984, vol. PAS-103, No. 7, pp. 1945-1952.

[10] E.B. Makram, R.L. Thompson, and A.A. Girgis, "A new laboratory experiment for transformer modeling in the presence of harmonic distortion using a computer controlled harmonic generator", in IEEE Transactions on Power Systems, November 1988, vol. 3, No. 4, pp. 1857-1863.

[11] O.W. Andersen, "Optimum design of electrical machines", in IEEE Transactions on Power Apparatus and Systems, June 1967, vol. PAS86, No. 6, pp. 707-711.

[12] A. Semlyen and H. Hamadanizadeh, "Computational experiments in 
power systems", in IEEE Transactions on Power Apparatus and Systems, September 1985, vol. PAS-104, No. 9, pp. 2290-2295.

[13] W.G. Hurley, W.H. Wölfle, and J.G. Breslin, "Optimized transformer design: Inclusive of high-frequency effects", in IEEE Transactions on Power Electronics, July 1998, vol. 13, No. 4, pp. 651-659.

[14] F.F. Judd and D.R. Kressler, "Design optimization of small lowfrequency power transformers", in IEEE Transactions on Magnetics, July 1977, vol. MAG-13, No. 4, pp. 1058-1069.

[15] R. Petkov, "Design issues of high-power high-frequency transformer", in Proc. 1995 International Conference on Power Electronics and Drive Systems, February 1995, vol. 1, pp. 401-410.

[16] Jr. A.S. Gilmour, "High-power, light-weight power conditioning", in IEEE Aerospace and Electronics Systems Magazine, December 1991, vol. 6, Issue 12 , pp. 33-39.

[17] H. O'Connor, "Advanced comprehensive design of line frequency transformers", in Electrical Insulation Conference 1997, and Electrical Manufacturing and Coil Winding Conference, September 1997, pp. 363-366.

[18] R. Asensi, J.A. Cobos, O. Garcia, R. Prieto, and J. Uceda, "A full procedure to model high frequency transformer windings", in IEEE 
Power Electronics Specialist Conference PESC'94, June 1994, vol. 2, pp. $856-863$.

[19] S.M. Miri, F. Lu, and B.E. Randall, "Design of low-leakage power supply transformers for high-precision electronic instruments", in IEEE Transactions on Instrumentation and Measurement, August 1993, vol. 42, No. 4 , pp. $854-859$.

[20] A. Basak, C.H. Yu, and G. Lloyd, "Efficient transformer design by computing core loss using a novel approach", in IEEE Transactions on Magnetics, September 1994, vol. 30, No. 5, pp. 3725-3728.

[21] R. Allcock, R. McClelland, S.A. Holland, and A. Roué, "Transformer design analysis using finite element methods", in IEE Colloquium on Computation in Electrostatics, 1995, pp. 8/1-8/3.

[22] M.P. Saravolac, "Use of advanced software techniques in transformer design", in IEE Colloquium on Design Technology of T\&D Plant, June 1998, pp. 9/1-9/11.

[23] G.R. Slemon and A. Straughen, Electric Machines, Addison-Wesley Publishing Company, Inc., USA, 1980.

[24] W.M. Flanagan, Handbook of Transformer Applications, McGraw-Hill, 1986. 
[25] C.R. Paul, S.A. Nasar, and L.E. Unnewehr, Introduction To Electrical Engineering, McGraw-Hill, Inc., Singapore, 1986.

[26] G.R. Slemon, Magnetoelectric Devices: Transducers, Transformers, and Machines, John Wiley and Sons, Inc., USA, 1966.

[27] M.G. Say, Alternating Current Machines, Longman Scientific \& Technical, Essex, England, 1983.

[28] F.C. Connelly, Transformers: Their Principles and Design for Light Electrical Engineers, Sir Isaac Pitman \& Sons Ltd, London, 1965.

[29] J. Hindmarsh, Electrical Machines and Their Applications, Pergamon Press, 3rd edition, 1977.

[30] P.T. Johnstone and P.S. Bodger, "High voltage disinfection of liquids", in IPENZ Transactions, November 1997, vol. 24, No. 1, EMCh, pp. $30-35$. 


\section{List of Figures}

1 Layout of core and windings of a transformer

2 Axial view of the transformer showing component dimensions and material properties

3 Transformer equivalent circuit, referred to the primary winding

4 Total core equivalent circuit 


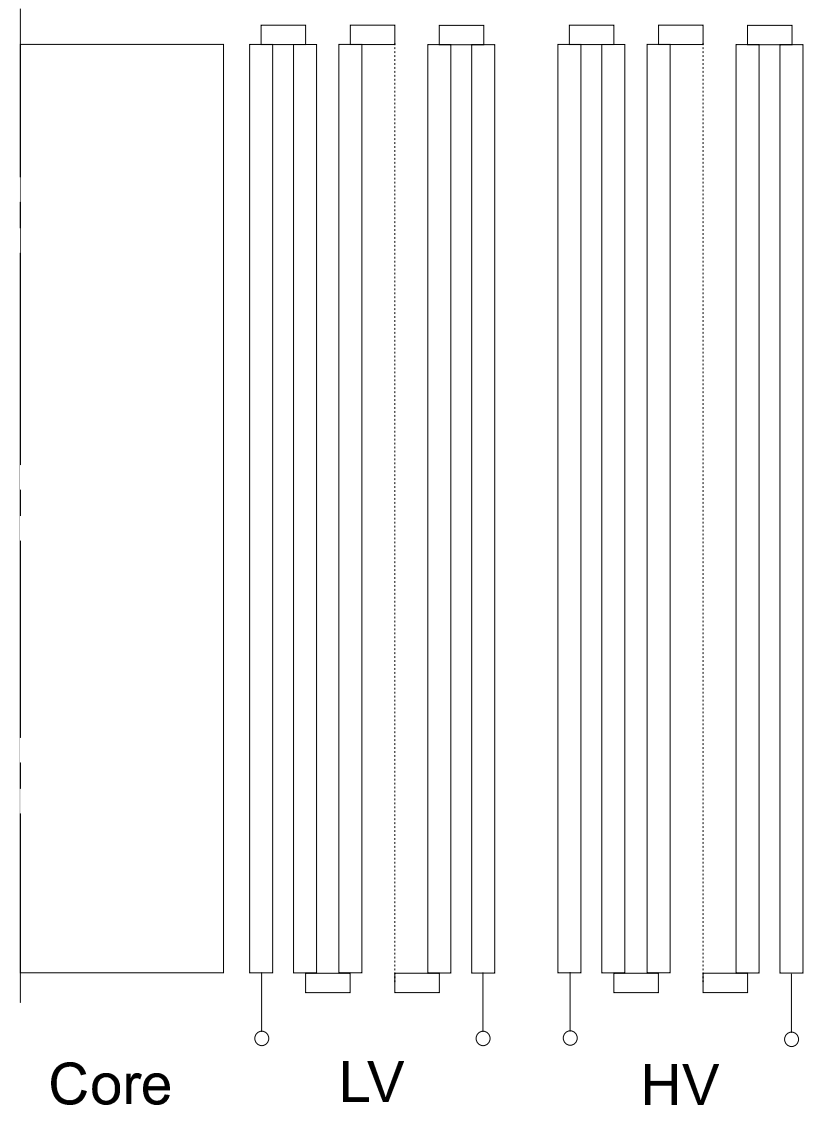

Figure 1: Layout of core and windings of a transformer 


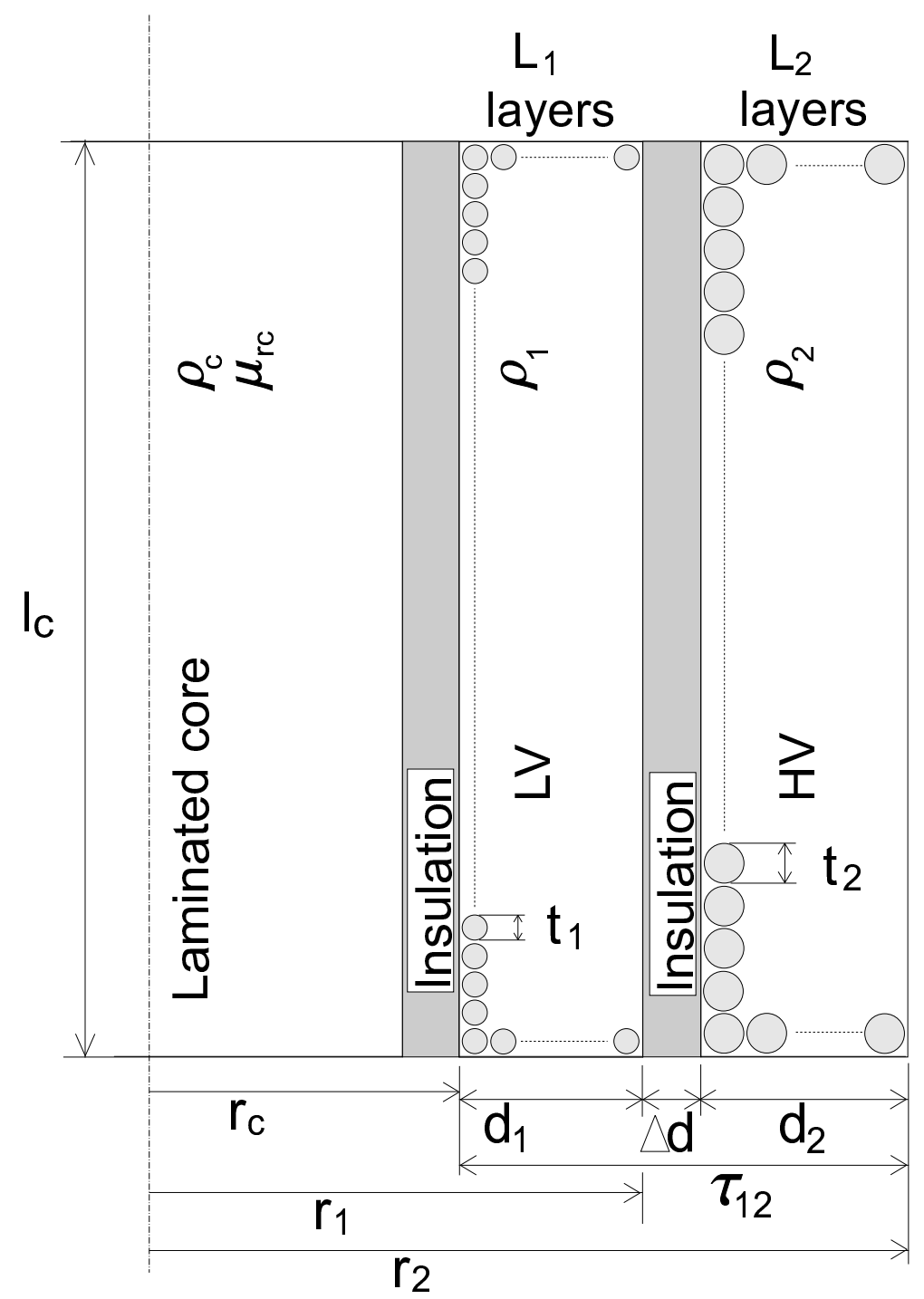

Figure 2: Axial view of the transformer showing component dimensions and material properties 


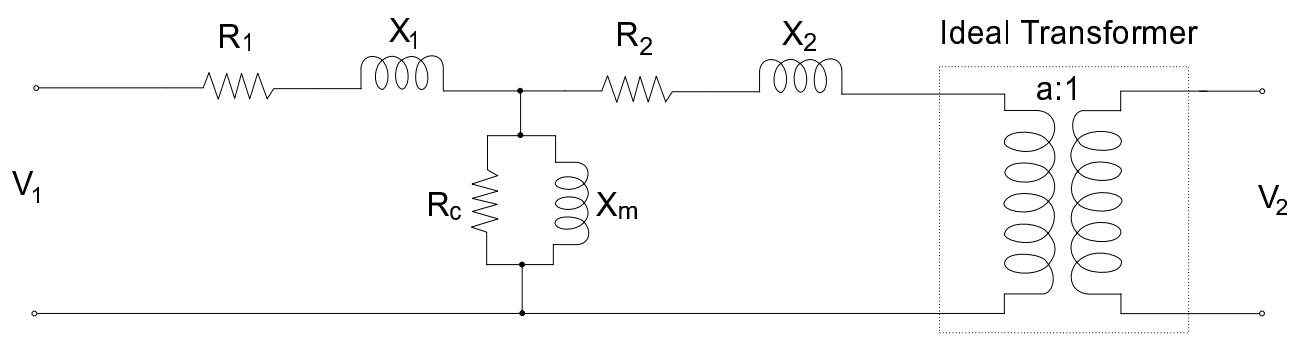

Figure 3: Transformer equivalent circuit, referred to the primary winding 


\section{Transformer core}

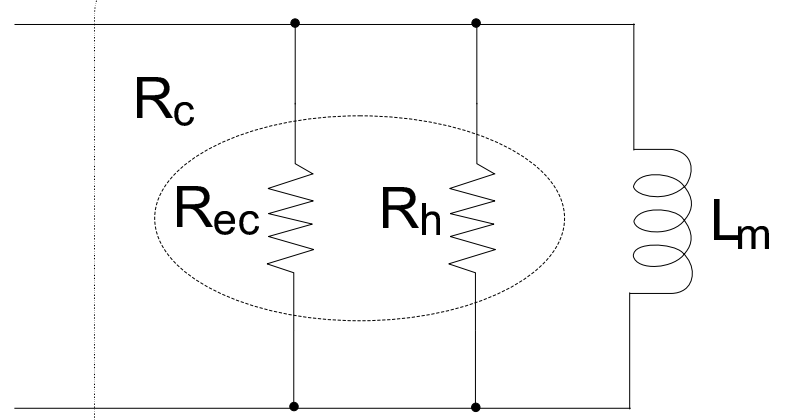

Figure 4: Total core equivalent circuit 